Article

\title{
Partial Discharge Analysis under High-Frequency, Fast-Rise Square Wave Voltages in Silicone Gel: A Modeling Approach
}

\author{
Moein Borghei and Mona Ghassemi * (D) \\ Department of Electrical and Computer Engineering, Virginia Tech, Blacksburg, VA 24061, USA; moeinrb@vt.edu \\ * Correspondence: monag@vt.edu
}

Received: 31 October 2019; Accepted: 28 November 2019; Published: 28 November 2019

check for updates

\begin{abstract}
Wide bandgap (WBG) power modules able to tolerate high voltages and currents are the most promising solution to reduce the size and weight of the power management and conversion systems. These systems are envisioned to be widely used in the power grid and the next generation of more (and possibly all) electric aircraft, ships, and vehicles. However, accelerated aging of silicone gel when being exposed to high frequency, fast rise-time voltage pulses that can offset or even be an obstacle for using WBG-based systems. Silicone gel is used to insulate conductor parts in the module and encapsulate the module. It has less electrical insulation strength than the substrate and is susceptible to partial discharges (PDs). PDs often occur in the cavities located close to high electric field regions around the sharp edges of metallization in the gel. The vulnerability of silicone gel to PDs occurred in the cavities under repetitive pulses with a high slew rate investigated in this paper. The objective mentioned above is achieved by developing a Finite-Element Analysis (FEA) PD model for fast, repetitive voltage pulses. This work has been done for the first time to the best of our knowledge. By using the model, the influence of frequency and slew rate on the magnitude and rate of PD events is studied.
\end{abstract}

Keywords: finite element analysis; partial discharge modeling; high-frequency; fast-rise square wave voltages; silicone gel; wide bandgap power modules

\section{Introduction}

The growing trend toward electrification has led to a rapid-growing penetration of power electronics into various residential, industrial, and commercial levels. In this regard, WBG power modules, which can tolerate higher voltages and currents than silicon (Si)-based modules, are the most promising solution for reducing the size and weight of power electronics systems. For example, while the highest breakdown voltage capability, known as the blocking voltage, for commercial Si insulated gate bipolar transistors (IGBT) is $6.5 \mathrm{kV}$, for SiC IGBTs is $15 \mathrm{kV}$ for $80 \mathrm{~A}$, and $24 \mathrm{kV}$ for $30 \mathrm{~A}$ [1]. While the blocking voltage of this $15-\mathrm{kV} \mathrm{SiC-IGBT}$ is 2.3 times higher than the Si-IGBT, its volume is one-third that for the Si-IGBT [1]. This translates into higher electric stress within the module. The high electric field, as well as its exposure to voltage pulses with high slew and repetition rates, create an extremely poor environment for insulation systems in envisioned high voltage high-density WBG modules where partial discharges (PDs) have the most impact on insulation degradation [2,3]. Two common insulation materials used in power modules are ceramic substrate and silicone gel. As the main insulation system, the ceramic substrate ensures electrical insulation between active components and the baseplate, which is generally grounded. Silicone gel is used for encapsulation to prevent electrical discharges in air and to protect substrates, semiconductors, and connections against humidity, dirt, and vibration. One of the weakest points inside the power electronics module, in terms of resistance against $\mathrm{PD}$, is the region 
in the silicone gel close to the sharp edges of metallization layers, as shown in Figure 1. These sharp edges lead to high electric field stress in the air-filled voids located in the mentioned regions that may initiate PDs within voids.

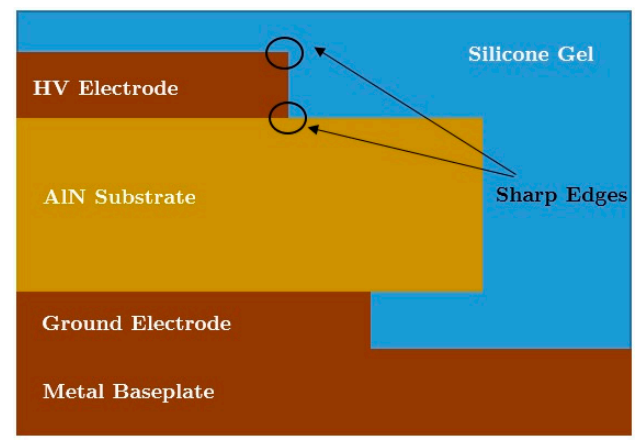

Figure 1. Schematic of an IGBT or a diode substrate.

One of the merits of WBG devices is that their slew rates and switching frequencies are much higher than Si-based devices. However, from the insulation side, frequency and slew rate are two of the most critical factors of a voltage pulse, which influences the level of degradation of the insulation systems that are exposed to such voltage pulses [4]. Solid dielectrics are found to be vulnerable to frequency, while the dominant factor for PD inception in liquid dielectrics is rising [5,6]. In this regard, the study of the insulation degradation of silicone gel, which has the properties of both liquids and solids can be challenging. The modeling of PD gains even more importance when knowing that the detection of PDs becomes very difficult under voltage pulses with short rise-times of tens to hundreds of ns [7].

The existence of voids and air bubbles is an inevitable phenomenon in dielectrics. They can be formed either during the manufacturing process or the streamer propagation itself. Aside from the manufacturing process, the electrical treeing itself causes the formation of air bubbles inside the dielectrics [8]. The experiments have shown that the self-healing characteristic of silicone gel cannot quickly omit the air bubbles. Even the cavity can grow due to the surface discharges occurring in silicone gel [9]. A cavity inside the silicone gel can last up to $10 \mathrm{~ms}$ that is 1000 times longer than that of non-viscous liquids [10]. PDs during this time may lead to the gradual degradation of silicone gel.

The air-filled cavities inside a dielectric are weak points due to their lower permittivity than the surrounding material. According to the enhancement factor introduced in Reference [11], the electric field in a spherical void inside the silicone gel can be enhanced by about $30 \%$ compared to the void-free case. Therefore, the impact of such voids on the expected lifetime of silicone gel should be taken into account.

Some methods, such as geometric techniques alone or combined with the application of nonlinear field-dependent conductivity layers, have been proposed to address the high electric field issue in envisioned high voltage high-density WBG power modules [12-19]. However, to the best of our knowledge, PD modeling for air-filled cavities in silicone gel, especially under fast, repetitive voltage pulses, still has not been reported. Elucidating and understanding mechanisms and phenomena behind PDs in air-filled cavities in silicone gel helps develop more efficient electric field control methods.

To accurately model the cavity-solid dielectric system, different models have been proposed [20-33]. In this paper, the FEA approach is utilized to dynamically model PDs inside a cavity located in silicone gel and calculate the electric field and potential distribution in different parts of the system. The parameters in the model are chosen and verified to be in agreement with the experimental results reported in the literature.

The model developed in COMSOL Multiphysics (5.4) interfaced with MATLAB (R2019b) provides the opportunity to examine the impact of fast, high-frequency voltage pulses on the initiation of PD from the standpoint of both intensity and number. 


\section{PD Initiation and Propagation}

When a discharge occurs, it takes place by the movement of free electrons and ions. These charged particles are formed due to the collisions between energetic electrons and neutral atoms. The free electrons in the presence of a high electric field gain enough energy to move rapidly and collide with neutral particles to form another electron as well as a positive ion. The electron avalanche process can occur when there is at least one free electron available and the electric field is sufficiently high to energize the electron for upcoming collisions. Later in this section, these two conditions are examined.

\subsection{Streamer Inception Criterion}

A PD does not completely bridge between the electrodes. PDs are local discharges that occur in defects or air-filled voids inside the dielectric material. From a physical point of view, a discharge occurs when a free electron is available while being energetic enough to ionize further molecules and cause the growth of the streamer. At high electric fields, electrons can gain a sufficient amount of energy for the collision and ionization of further atoms or molecules, as shown in Figure 2.

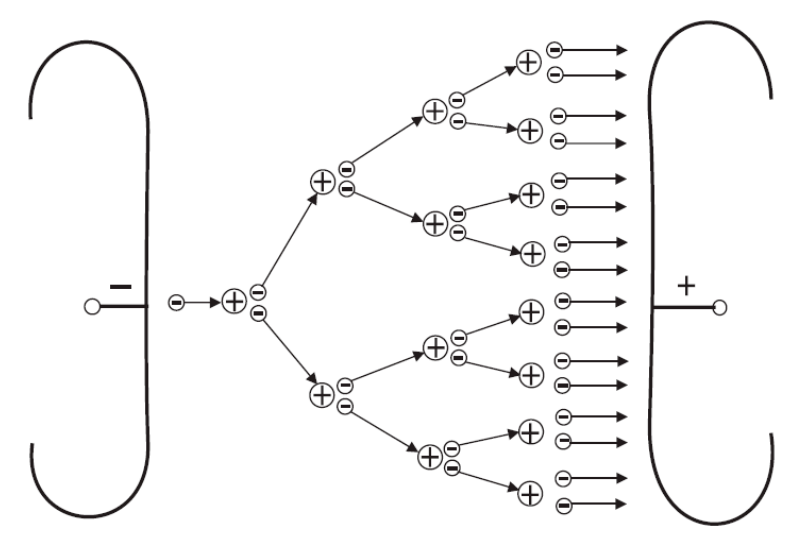

Figure 2. Streamer formation between two electrodes.

Thus, for modeling the inception time of PDs correctly, it is necessary to have an accurate representation of the electric field magnitude at which the impact ionization process can be begun. In this regard, a critical avalanche criterion has been proposed in Reference [21] that probes into the critical number of electrons needed for the head of an avalanche to be self-propagating [11]. Satisfying the mentioned requirement, the streamer inception criterion can be expressed concisely as follows.

$$
\frac{E_{i n c}}{E_{c r}}=F
$$

The ratio of the PD inception field to the critical field at which total breakdown happens is defined by a dimensionless parameter, $F$, a function of gas inside the cavity, permittivity of the dielectric, and the defect geometry. For a spherical cavity, it can be defined by the equation below.

$$
F=1+\frac{B}{(p d)^{n}}
$$

where $B$ and $n$ are constants related to gas. For air, they are equal to $8.6 \mathrm{~Pa}^{0.5} \mathrm{~m}^{0.5}$ and 0.5 , respectively [11]. The gas pressure $p$ and defect diameter parallel to background field $d$ are the other parameters used in this model.

It should be mentioned that environmental conditions can have a considerable contribution to the ionization process. As found in Reference [27], the existence of humidity can reduce the breakdown voltage of silicone gel. 


\subsection{Initial Free-Electron}

Along with the streamer inception criterion, another condition must also be satisfied to guarantee that the ionization process happens. It evaluates the existence of at least one free electron for the initiation of discharge. Therefore, even after exceeding the inception field, the occurrence of PD might be associated with a statistical time delay related to the second criterion of PD inception.

The initial electron can be provided in various ways. Radiative ionization is one of the processes to generate the initial electrons. Irradiation of energetic photons can ionize molecules, and the rate of electrons per unit of time that can be generated through this mechanism is formulated below [28].

$$
N_{\text {rad }}=K_{\text {rad }}(\rho / p)_{0} p V_{\text {cav }}\left(1-\mu^{-0.5}\right)
$$

where $K_{r a d}$ is a constant characterizing the irradiation process, $(\rho / p)_{0}$ is the pressure reduced density of the gas, $V_{c a v}$ is the volume of the cavity, and $\mu$ is the overvoltage factor.

Aside from the photon radiation, the initial electron can be provided through the de-trapping of electrons from the surface cavity. These electrons are remnants of previous PD events that are positioned into the traps at the cavity surface. The number of electrons remaining from a previous PD is obtained as:

$$
N_{P D}=\frac{q_{P D}}{e} e^{-\frac{t-t_{P D}}{\tau_{d e c}}}
$$

The number of electrons remained from a PD event is linearly dependent upon the true PD charge magnitude $\left(q_{P D}\right)$. It is also affected by time. As the time passes from its occurrence, the number of available electrons is decreased by different decay mechanisms such as moving the electrons into deeper traps from which the electrons cannot be further de-trapped.

The emission of electrons from the surface of the cavity has been found to follow Richardson-Schottky scaling [19]. Thus, the rate of electron emission from the surface of the cavity due to de-trapping of remnant electrons can be formulated by the equation below.

$$
N_{d t r}=N_{P D} v_{0} e^{-\frac{\phi-\sqrt{e} \frac{\mid E[c a v(t) \mid}{4 \pi \varepsilon_{0}}}{k T}}
$$

In the formulation above, $v_{0}$ is the fundamental phonon frequency, and $\phi$ is the de-trapping work function. The Boltzmann constant and absolute temperature are denoted by $k$ and $T$, respectively. Moreover, as shown in Equation (6), the rate of electron emission relies on the magnitude of the electric field inside the cavity. The higher the electric field, the higher the probability of electron detachment.

Then, the total rate of electron generation can be approximately yielded by summation of the electron generation rate due to each of these processes.

$$
\dot{N}_{e}=\dot{N}_{\text {rad }}+\dot{N_{d t r}}
$$

The final step in the assessment of free electron availability is to address the stochastic nature of the phenomena. At the first step, the probability of the existence of a free electron for PD ignition $(P)$ at each time step ought to be obtained [27].

$$
P=1-\exp \left(-\int_{0}^{t} \dot{N}_{e}(t) \cdot d t\right)
$$

At the second step, a random number $R$ between zero and unity is generated and will be compared to $P$. If $P$ is greater than $R$, then the PD happens. 


\section{Modeling of the PD Process}

The actions of a PD are associated with an increase in cavity conductivity, which leads to a voltage drop and a field reduction across the cavity. To accurately model this, once the two conditions for PD ignition are satisfied, the conductivity of the cavity is increased from its initial value (close to zero) to a maximum level $\left(\sigma_{\text {cav }, m}\right)$.

Moreover, one should take into account the charge decay mechanism. The accumulated charges on the surface of the cavity do not have an infinite lifetime. They might decay through conduction along the cavity wall by the movement of electrons from shallow traps into deeper ones [29]. This process is found to be dependent upon the magnitude of charges deposited on the cavity surface. If the magnitude of the physical charge exceeds a certain value, $Q_{c r}$, the surface conductivity is increased to a higher magnitude, $\sigma_{\text {surf }, H}$ [30]. Once the charge magnitude drops below the threshold, the surface conductivity comes back to its initial value. Using FEA, the charge magnitude at each instant can be obtained through the integration of field displacement over the cavity surface area.

The entire PD modeling procedure is demonstrated in Figure 3. Starting from the origin of time, the FEA model is run to enable the assessment of the two PD requirements (i.e., streamer criterion as well as the initial electron availability). If any of the two prerequisites are not satisfied, the algorithm goes to the next time step. The procedure of looking for a PD is continued until finding a time instant that meets the requirements or the program runs out of time steps. Once the occurrence of a PD event is guaranteed, the cavity and surface conductivities are updated. Afterward, the FEA is again run to find the extinction time of the PD. Note that a state variable (shown in Figure 3) is employed to distinguish between the state of looking for the initiation of the next PD event $($ state $=0)$ and the state of looking for the extinction time of a current PD (state $=1)$. Moreover, it should be noted that the time step does not have a constant value. There are two values for the time step. One is the time step between PD events $\left(\Delta t_{L}\right)$ and the other is the time step during PD activities $\left(\Delta t_{H}\right)$. Since the duration of PD events are much smaller than the time interval between PD events, $\Delta t_{L}$ is expected to be larger than $\Delta t_{H}$.

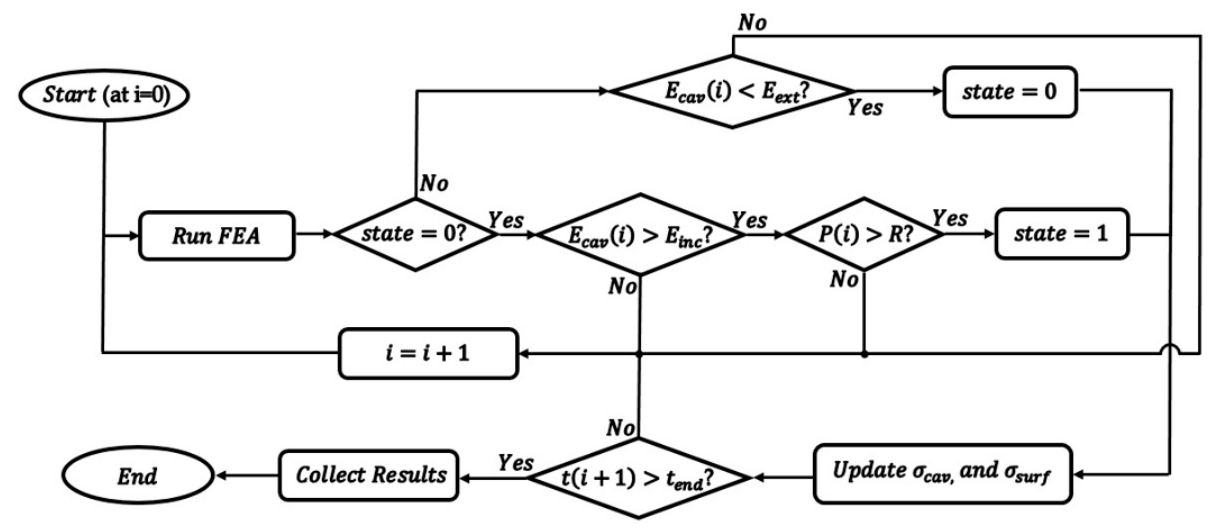

Figure 3. PD modeling flowchart.

\section{Results and Key Challenges}

\subsection{Case Study}

The case study considered in this paper consists of a sphere-sphere electrode system that provides a weakly non-uniform electric field. A spherical air-filled cavity is located between the electrodes. The configuration of the system is shown in Figure 4, and the related parameters are listed in Table 1. For FEA, the 2D-axisymmetrical representation of the configuration is used. The parameters related to electron generation rate, time-stepping, and charge decay are listed in Table 2. The details and representation of the mesh are shown in Table 3 and Figure 5, respectively. 


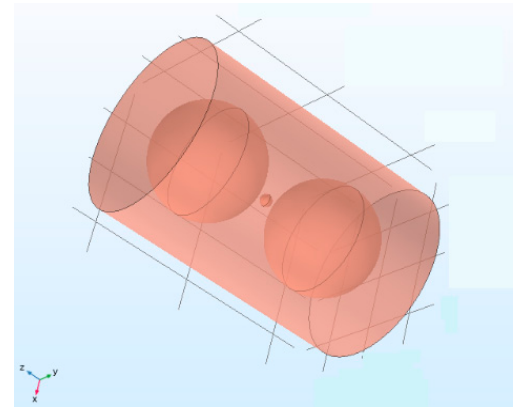

(a)

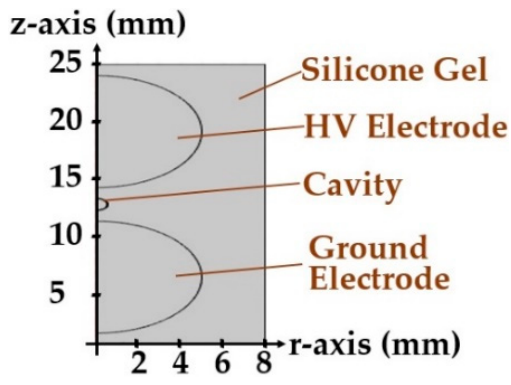

(b)

Figure 4. The graphical representation of the case study. (a) 3D and (b) Axi-symmetrical 2D.

Table 1. Case Study Parameters.

\begin{tabular}{ccc}
\hline Symbol & Parameter & Value \\
\hline$d_{c a v}$ & Geometrical \\
$r_{e l}$ & cavity diameter & $1 \mathrm{~mm}$ \\
$d$ & electrode radius & $5 \mathrm{~mm}$ \\
$\varepsilon_{r}$ & distance between electrodes & $3 \mathrm{~mm}$ \\
$\sigma_{0}$ & Silicone gel & 2.8 \\
$U_{\text {peak }}$ & relative permittivity & $10^{-13} \mathrm{~S} / \mathrm{m}$ \\
$f$ & conductivity & $11 \mathrm{kV}$ \\
$r_{t}$ & Applied Voltage & $20 \mathrm{kHz}$ \\
$D$ & voltage peak magnitude & $100 \mathrm{~ns}$ \\
\hline
\end{tabular}

Table 2. Parameters of PD Model.

\begin{tabular}{cc}
\hline Symbol & Value \\
\hline$E_{\text {cr }}$ & $2.42 \times 10^{6} \mathrm{~V} / \mathrm{m}$ \\
$K_{\text {rad }}$ & $2 \times 10^{6} \mathrm{~kg}^{-1} \mathrm{~s}^{-1}$ \\
$(\rho / p)_{0}$ & $10^{-5} \mathrm{~kg} \mathrm{~m}^{-3} \mathrm{~Pa}^{-1}$ \\
$p$ & $1 \mathrm{~atm}$ \\
$\tau_{\text {dec }}$ & $0.15 T$ \\
$\phi$ & $1.3 \mathrm{eV}$ \\
$v_{0}$ & $10^{14} \mathrm{~s}^{-1}$ \\
$T$ & $300 \mathrm{~K}$ \\
$\Delta t_{L}$ & $1 /(1000 f)$ \\
$\Delta t_{H}$ & $1 \mathrm{~ns}$ \\
$\sigma_{\text {cav }, m}$ & $0.0004 \mathrm{~S} / \mathrm{m}$ \\
$\sigma_{\text {surf }, L}$ & $2 \times 10^{-13} \mathrm{~S} / \mathrm{m}$ \\
$\sigma_{\text {surf }, H}$ & $10^{-11} \mathrm{~S} / \mathrm{m}$ \\
$E_{\text {inc }}$ & $3.1 \mathrm{kV} / \mathrm{mm}$ \\
$E_{\text {ext }}$ & $0.1 \mathrm{kV} / \mathrm{mm}$ \\
\hline
\end{tabular}

Table 3. Mesh Properties.

\begin{tabular}{cc}
\hline Quantity & Value \\
\hline Maximum element size & $5 \times 10^{-4} \mathrm{~m}$ \\
Minimum element size & $1.88 \times 10^{-6} \mathrm{~m}$ \\
Maximum element growth rate & 1.2 \\
Curvature factor & 0.25 \\
Resolution of narrow regions & 1 \\
Maximum element size & $5 \times 10^{-4} \mathrm{~m}$ \\
\hline
\end{tabular}




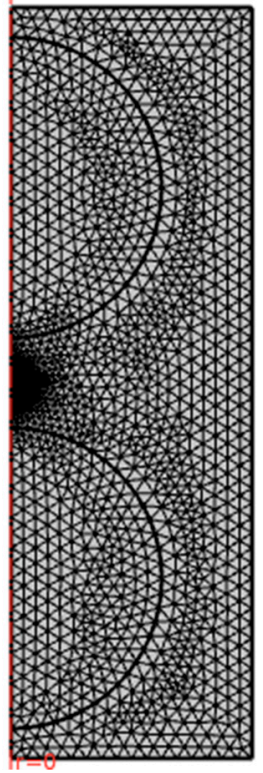

Figure 5. Mesh Pattern of the void-dielectric system.

\subsection{Results}

\subsubsection{Field Distribution before and after PD}

The electric field distribution is shown in Figure 6 right before and right after PD occurrence. As expected, the electric field intensity inside the cavity is higher than the surrounding material, and it increases up to a point where the cavity can no longer withstand the electric stress. With the availability of an initial electron, the collision between electrons and molecules is begun, which gives rise to an increase in the cavity conductivity, and loses its insulating property, subsequently.

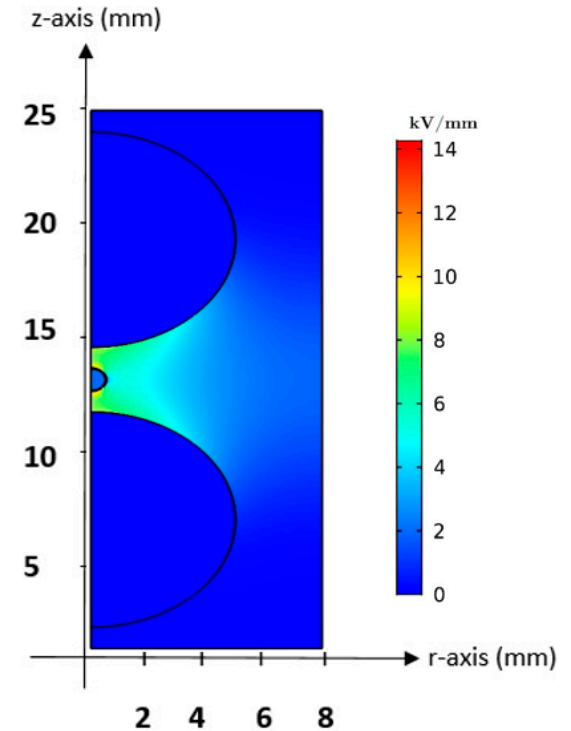

(a)

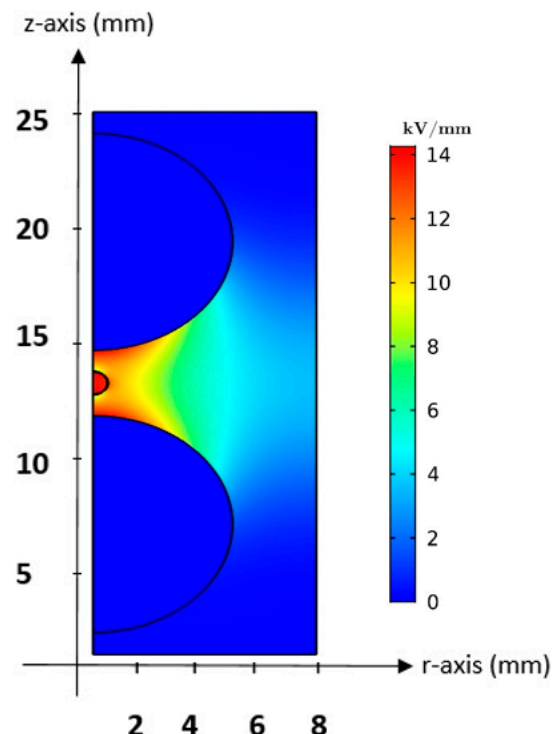

(b)

Figure 6. The electric field distribution (a) before, and (b) after PD occurrence.

The reduction of cavity electric resistance causes the electric field and voltage across the cavity to drop. It is continued until the electric field has reached the extinction field. 


\subsubsection{Discharge Pulses over Time for 20 Cycles}

A summary of results is reported in Table 4. In this table, the true and apparent charge magnitudes are used to illustrate the intensity of PD activities. The true charge magnitude is the amount of charge accumulated on the upper or lower cavity hemisphere while the apparent charge magnitude is the charge magnitude accumulated over the surface of the ground electrode. In addition, Figure 7 shows the phase-resolved PD (PRPD) pattern that is in good agreement with the experiments reported in Reference [34]. Two PDs occur at each cycle. One occurs at the rising flank of the pulse, and the other one occurs at the falling flank. To date, PD activity was not modeled under fast, high-frequency voltage pulses to the best of our knowledge, and this paper models it for the first time.

Table 4. Results of PD simulation.

\begin{tabular}{cc}
\hline Quantity & Value \\
\hline Number of PDs per cycle & 1.9866 \\
Mean duration of PD & $503.67 \mathrm{~ns}$ \\
Mean true charge & $0.42 \mu \mathrm{C}$ \\
Mean apparent charge & $14.88 \mu \mathrm{C}$ \\
Maximum true charge & $2.46 \mu \mathrm{C}$ \\
Maximum apparent charge & $86.58 \mu \mathrm{C}$ \\
\hline
\end{tabular}

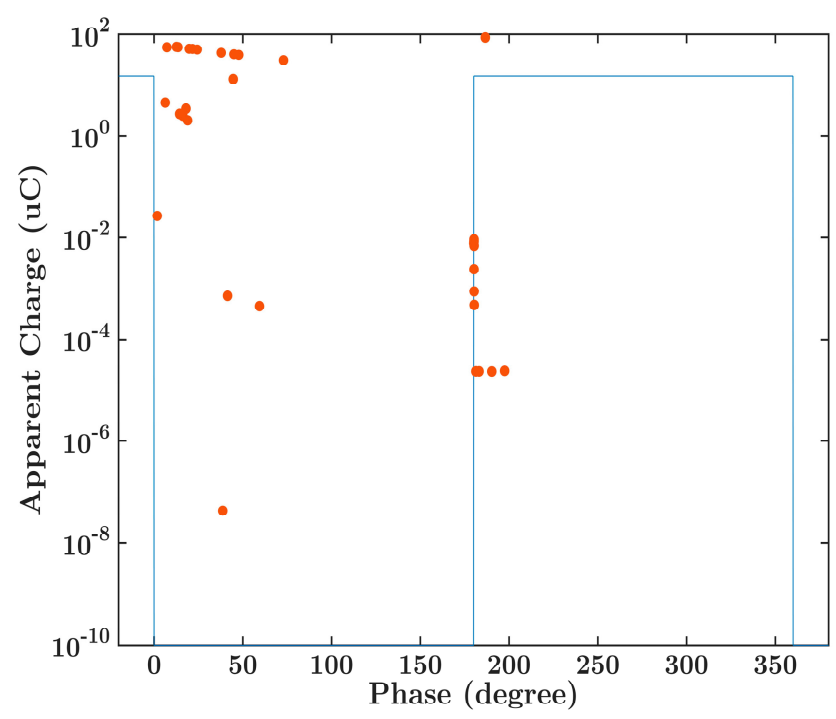

Figure 7. Phase-resolved PD (PRPD) Pattern.

While the magnitudes of PD charges are very similar to each other, Figure 7 conveys the fact that the statistical time lag is much higher in the falling flank. This can be justified through the need for an initial free electron that is harder to obtain at the falling flank due to the charge decay process reducing the emission of electrons from the surface due to the last discharge.

\subsubsection{Rise-Time and Frequency Impact}

As seen in Figure 8, the destructive impact of frequency and rise-time on PD charge magnitude is clear. However, among these two factors, frequency is more detrimental at its high values. The number of PDs per cycle may decrease by a frequency enhancement, while the severity of PDs may be escalated. 


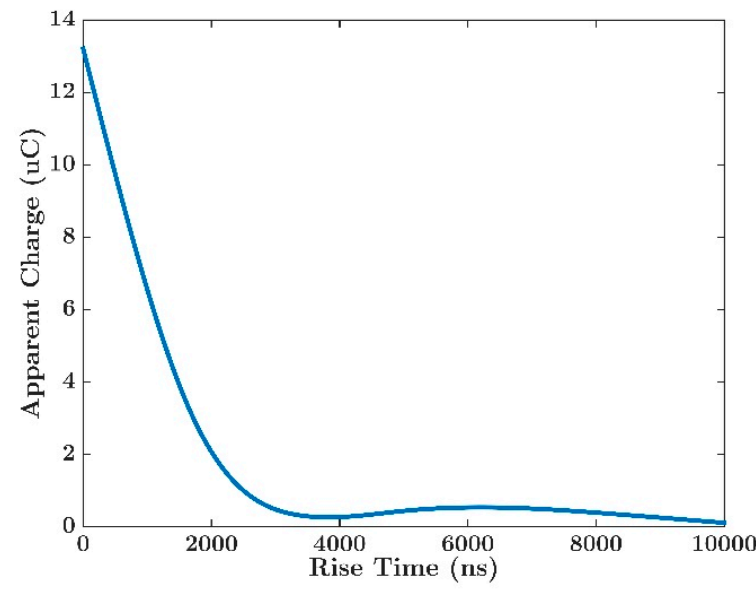

(a)

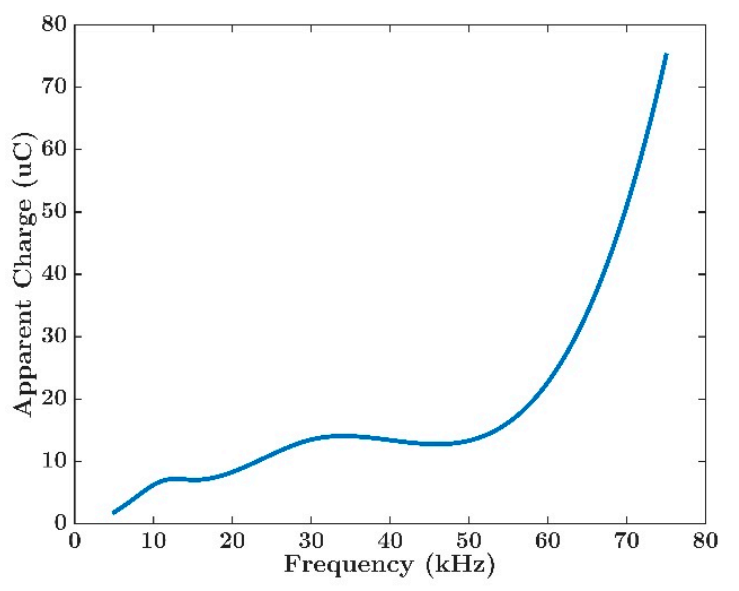

(b)

Figure 8. The effect of (a) frequency, and (b) rise-time on PD intensity.

\subsection{Key Challenges}

\subsubsection{Estimation of Model Parameters}

One of the main steps to be taken to reach reliable results for PD simulation is the valid estimation of the physical parameters associated with the model. To accurately determine the value of these parameters, the adjustment of the model with the experimental data can be a feasible criterion.

Each of the physical parameters may contribute to one or more of the PD characteristics (e.g., inception, magnitude, duration, etc.). In this regard, the results reported in Reference [35] were utilized for the purpose of parameter estimation. In the previously mentioned paper, Figure 7 represents the phase-resolved PD (PRPD) pattern for a silicone gel dielectric within two spherical electrodes. The applied voltage is reported to be $11 \mathrm{kV}$ and the PD is found to be activated when the applied voltage reaches $9.5 \mathrm{kV}$.

The degrees of freedom are determined by the number of indices that are used for the adjustment. Among the parameters, cavity conductivity during $\operatorname{PD}\left(\sigma_{c a v, m}\right)$, the cavity inception field $\left(E_{\text {inc }}\right)$, the cavity extinction field $\left(E_{\text {ext }}\right)$, and the decay time constant $\left(\tau_{d e c}\right)$ are found to be appropriate for modeling. $\sigma_{c a v, m}$ helps control the magnitude and duration of PD events. The higher $\sigma_{c a v, m}$ is, the quicker the electric field drops inside the cavity. However, the current density over the cavity wall decreases with the increase in $\sigma_{c a v, m}$.

$E_{\text {inc }}$ can help determine the inception time. As mentioned, the PD occurs at a voltage of $9.5 \mathrm{kV}$, and the field at which the voltage reaches this value is chosen as $E_{\text {inc }}$. On the other hand, $E_{\text {ext }}$ can contribute to the length of $\mathrm{PD}$, which can also enhance the magnitude of discharges.

Lastly, the time constant can take part in the inception time of PD events. The longer the time constant, the higher the chances of free-electron availability.

Assuming the mean charge magnitude at each half cycle, the proportionality of the number of PDs at half cycles, and the inception voltage, the four degrees of freedom $\left(\sigma_{c a v, m}, E_{i n c}, E_{\text {ext }}\right.$, and $\left.\tau_{\text {dec }}\right)$ are used by fitting the experimental indices.

The values mentioned in Table 4 are determined after adjusting these parameters to the model. Figure 9 demonstrates the PRPD pattern obtained after running the developed model for 50 cycles of the applied voltage, which shows acceptable agreement with the PRPD pattern reported in Reference [35]. 


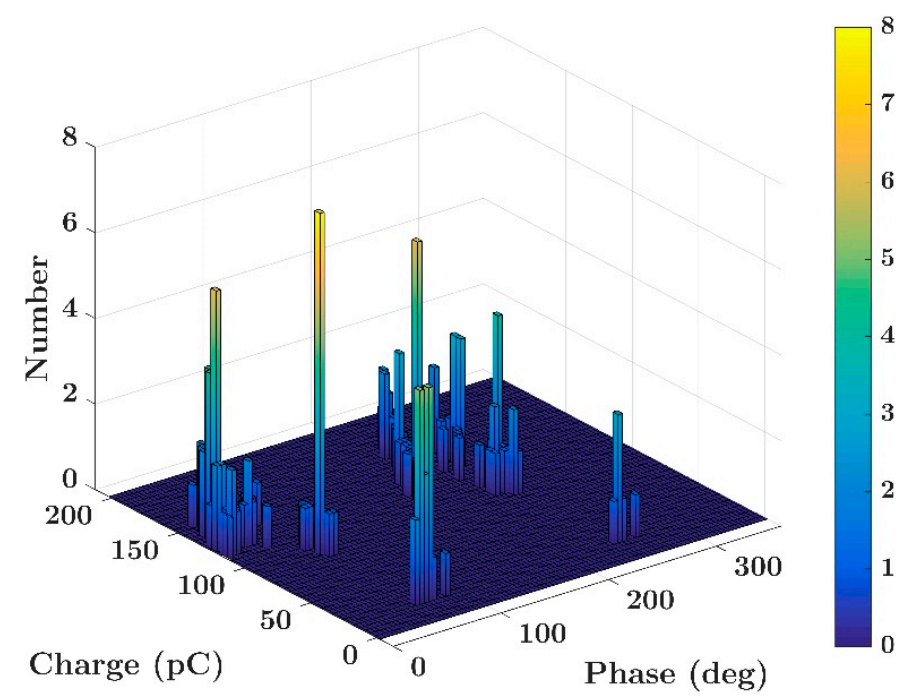

Figure 9. The 3D PRPD pattern for the case study in Reference [12] after 50 cycles.

\subsubsection{Convergence Problem}

Based on the algorithm described in this paper, the time steps are strictly determined by the algorithm process. While a degree of freedom could help choose those time steps that have higher chances to meet the error tolerance, the strict way of time stepping may enforce convergence problems.

There are multiple ways to overcome these challenges including using a more precise mesh to enhance the convergence chance. In addition, the time-stepping method itself might be capable of providing an opportunity to resolve the convergence problem. In this paper, the time-stepping method employed to solve the time-dependent set of numerous algebraic equations is a method called generalized- $\alpha$, which is coupled with the first-order and second-order nonlinear differential equations.

This method was first developed by Chung and Hulbert for solving structural dynamics problems in 1993 [36]. This is an implicit method for solving transient problems and attempts to control the damping extent $(0 \leq \xi<1)$ at high-frequencies without a significant influence on the order of accuracy. While this method is more accurate than the Backward Differentiation Formula (BDF) due to its lower damping, it is less stable for the same reason. Thus, alongside the potential of mesh properties, the generalized- $\alpha$ method is used in this paper in order to resolve the convergence problem by increasing the damping frequency.

\subsubsection{Burden of Calculation}

Since the PD phenomenon has a memory over the previous PD events, an accurate model cannot probe into each event in an isolated manner.

On the other hand, over the course of time, the time instants under investigation grow extensively larger, which makes the FEA more time-consuming. In order to prevent the excessive burden of calculation, one must assess the role of previous PD events on the occurrence and intensity of the upcoming PD event in the first place.

Once the calculations related to a PD event are performed, its contribution to the next discharges can be categorized into two parts. The first one is the role of the PD event in the correct modeling of the changes in voltage distribution and the transition between consecutive PD events. The second contribution is due to its role in the provision of initial free electrons for the upcoming PD, which helps estimate the likelihood of a PD occurrence conducted within the programming section.

In order to accurately model the voltage distribution, the voltage transient associated with each of the discharges should be modeled. However, to model the previous PD events, it is not necessary to have the same number of time instants as in the case of searching for the next PD event. Therefore, a lower number of time instants should be adopted, which is enough to model the transition of the 
cavity state from non-conducting to conducting and again to a non-conducting state. These changes can be modeled through a lower number of time instants $\left(N_{\text {comp }}\right)$. In this way, the feasibility of applying the proposed model at a high number of cycles is maintained.

Figure 10 compares the computation time in the case of using the compaction technique $\left(N_{\text {comp }}=20\right)$ to the case of using the exhaustive approach. All the simulations are performed using a computer system with a processor operating at $3.1 \mathrm{MHz}$ with a Random-access memory (RAM) of 24 GBs.

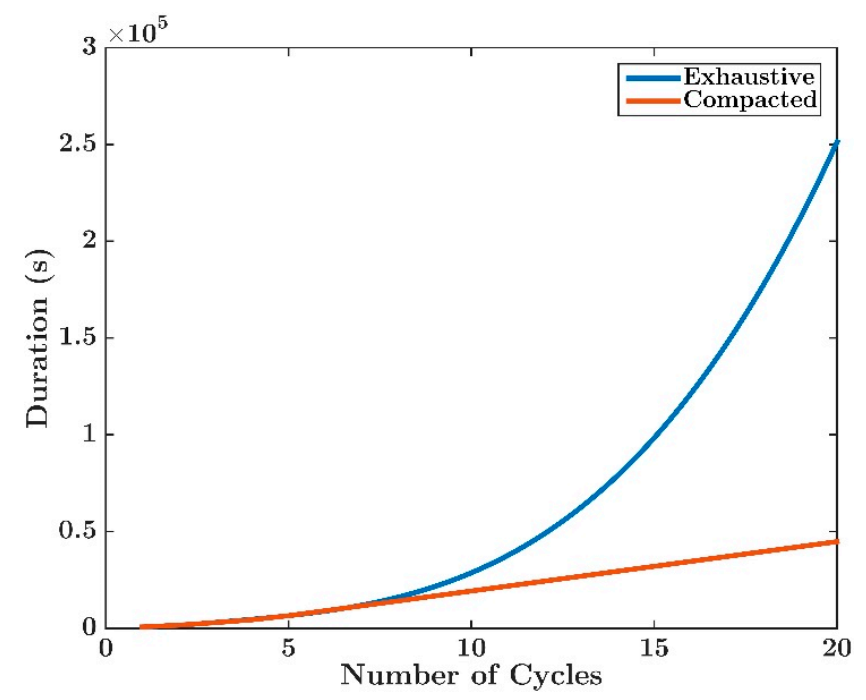

Figure 10. The impact of the compaction technique on computation time.

\section{Conclusions}

The crucial role of power electronics in the future needs the examination of power modules from different perspectives to ensure the proper operation of the system. As the new generations of modules benefit from WBG semiconductors operating at higher voltages, frequencies, and temperatures, it is necessary to scrutinize the electric stress supported by the insulation system. This paper, using a modeling approach with the aid of simulation tools, probed into a destructive phenomenon, named PD, that can happen inside the power module. In this paper, a PD model was proposed based on the physical processes taking place during the PD phenomena. The model was adjusted to the experimental results reported in the literature. From the obtained results, it is clear that the frequency and rise-time can have a destructive impact on the health of dielectric. The novel modeling approach proposed in this paper, which is done for the first time in the case of fast-rise, high-frequency square voltage, can be the groundwork for any power electronic module design to ensure its reliable operation from the standpoint of insulation performance.

Author Contributions: The authors contributed equally to this work in all parts.

Funding: This research received no external funding.

Conflicts of Interest: The authors declare no conflict of interest.

\section{References}

1. Passmore, B.; O’Neal, C. High-Voltage SiC Power Modules for 10-25 kV Applications. Power Electron. Europe Mag. 2016, 1, 22-24.

2. Ghassemi, M. PD Measurements, Failure Analysis, and Control in High-Power IGBT Modules. High Volt. 2018, 3, 170-178. [CrossRef] 
3. Ghassemi, M. Electrical Insulation Weaknesses in Wide Bandgap Devices. In Simulation and Modelling of Electrical Insulation Weaknesses in Electrical Equipment; Albarracin, R., Ed.; IntechOpen: London, UK, 2018; pp. 129-149.

4. Ghassemi, M. Accelerated Insulation Aging Due to Fast, Repetitive Voltages: A Review Identifying Challenges and Future Research Needs. IEEE Trans. Dielectr. Electr. Insul. 2019, 26, 1558-1568. [CrossRef]

5. Mancinelli, P.; Cavallini, A.; Dodd, S.J.; Chalashkanov, N.M.; Dissado, L.A. Analysis of Electrical Tree Inception in Silicone Gels. IEEE Trans. Dielectr. Electr. Insul. 2017, 24, 3974-3984. [CrossRef]

6. Madonia, A.; Romano, P.; Hammarström, T.; Gubanski, S.M.; Viola, F.; Imburgia, A. PD characteristics at square shaped voltages applying two different detecting techniques. In Proceedings of the IEEE Conference on Electrical Insulation and Dielectric Phenomena (CEIDP), Toronto, ON, Canada, 16-19 October 2016; pp. 247-250.

7. Hammarström, T.J.Å. Partial Discharge Characteristics at Ultra-Short Voltage Rise Times. IEEE Trans. Dielectr. Electr. Insul. 2018, 25, 2241-2249. [CrossRef]

8. Dodd, S.J.; Salvatierra, L.; Dissado, L.A.; Mola, E. Electrical trees in silicone gel: A combination of liquid and solid behaviour patterns. In Proceedings of the IEEE Conference on Electrical Insulation and Dielectric Phenomena (CEIDP), Shenzhen, China, 20-23 October 2016; pp. 1018-1021.

9. Sato, M.; Kumada, A.; Hidaka, K.; Yamashiro, K.; Hayase, Y.; Takano, T. Degradation process of silicone-gel by internal surface discharges. In Proceedings of the IEEE International Conference on Dielectric Liquids (ICDL), Bled, Slovenia, 29 June-3 July 2014; pp. 1-4.

10. Wang, N.; Cotton, I.; Robertson, J.; Follmann, S.; Evans, K.; Newcombe, D. Partial Discharge Control in a Power Electronic Module Using High Permittivity Non-Linear Dielectrics. IEEE Trans. Dielectr. Electr. Insul. 2010, 17, 1319-1326. [CrossRef]

11. Niemeyer, L. A Generalized Approach to Partial Discharge Modeling. IEEE Trans. Dielectr. Electr. Insul. 1995, 2, 510-528. [CrossRef]

12. Ghassemi, M. Geometrical techniques for electric field control in (ultra) wide bandgap power electronics modules. In Proceedings of the IEEE Electrical Insulation Conference (EIC), San Antonio, TX, USA, 17-20 June 2018; pp. 589-592.

13. Tousi, M.M.; Ghassemi, M. Electric field control by nonlinear field dependent conductivity dielectrics characterization for high voltage power module packaging. In Proceedings of the IEEE International Workshop on Integrated Power Packaging (IWIPP), Toulouse, France, 24-26 April 2019; pp. 54-58.

14. Tousi, M.M.; Ghassemi, M. Nonlinear field dependent conductivity materials for electric field control within next-generation wide bandgap power electronics modules. In Proceedings of the 2019 IEEE Electrical Insulation Conference (EIC), Calgary, AB, Canada, 16-19 June 2019; pp. 63-66.

15. Tousi, M.M.; Ghassemi, M. Electrical insulation packaging for a $20 \mathrm{kV}$ high density wide bandgap power module. In Proceedings of the IEEE Energy Conversion Congress \& Exposition (ECCE), Baltimore, MD, USA, 29 September-3 October 2019; pp. 4162-4166.

16. Tousi, M.M.; Ghassemi, M. Nonlinear resistive electric field grading in high-voltage, high-power wide bandgap power module packaging. In Proceedings of the IEEE Energy Conversion Congress \& Exposition (ECCE), Baltimore, MD, USA, 29 September-3 October 2019; pp. 7124-7129.

17. Tousi, M.M.; Ghassemi, M. The effect of type of voltage (sinusoidal and square waveform) and the frequency on the performance of nonlinear field-dependent conductivity coatings for electric field control in power electronic modules. In Proceedings of the IEEE Conference on Electrical Insulation and Dielectric Phenomena (CEIDP), Richland, DC, USA, 20-23 October 2019; pp. 601-604.

18. Tousi, M.M.; Ghassemi, M. Combined Geometrical Techniques and Applying Nonlinear Field Dependent Conductivity Layers to Address the High Electric Field Stress Issue in High Voltage High-Density Wide Bandgap Power Modules. IEEE Trans. Dielectr. Electr. Insul. 2019, in press.

19. Tousi, M.M.; Ghassemi, M. Characterization of Nonlinear Field Dependent Conductivity Layer Coupled with Protruding Substrate to Address High Electric Field Issue within High Voltage High-Density Wide Bandgap Power Modules. IEEE J. Emerg. Sel. Top. Power Electron. 2019, in press. [CrossRef]

20. Whitehead, S. Dielectric Breakdown in Solids; Clarendon Press: Oxford, UK, 1951.

21. Crichton, G.C.; Karlsson, P.W.; Pedersen, A. Partial Discharges in Ellipsoidal and Spheroidal Voids. IEEE Trans. Electr. Insul. 1989, 24, 335-342. [CrossRef] 
22. Pedersen, A.; Crichton, G.C.; McAllister, I.W. The Theory and Measurement of Partial Discharge Transients. IEEE Trans. Electr. Insul. 1991, 26, 487-497. [CrossRef]

23. Pedersen, A.; Crichton, G.C.; McAllister, I.W. The Functional Relation Between Partial Discharges and Induced Charge. IEEE Trans. Dielectr. Electr. Insul. 1995, 2, 535-543. [CrossRef]

24. Gutfleisch, F.; Niemeyer, L. Measurement and Simulation of PD in Epoxy Voids. IEEE Trans. Dielectr. Electr. Insul. 1995, 2, 729-743. [CrossRef]

25. Achillides, Z.; Danikas, M.G.; Kyriakides, E. Partial Discharge Modeling and Induced Charge Concept: Comments and Criticism of Pedersen's Model and Associated Measured Transients. IEEE Trans. Dielectr. Electr. Insul. 2017, 24, 1118-1122. [CrossRef]

26. Achillides, Z.; Kyriakides, E.; Georghiou, G.E. Partial Discharge Modeling: An Improved Capacitive Model and Associated Transients along Medium Voltage Distribution Cables. IEEE Trans. Dielectr. Electr. Insul. 2013, 20, 770-781. [CrossRef]

27. Finis, G.; Claudi, A. On the Dielectric Breakdown Behavior of Silicone Gel Under Various Stress Conditions. IEEE Trans. Dielectr. Electr. Insul. 2007, 14, 487-494. [CrossRef]

28. Schifani, R.; Candela, R.; Romano, P. On PD Mechanisms at High Temperature in Voids Included in an Epoxy Resin. IEEE Trans. Dielectr. Electr. Insul. 2001, 8, 589-597. [CrossRef]

29. Illias, H.; Chen, G.; Lewin, P.L. Partial Discharge Behavior Within a Spherical Cavity in a Solid Dielectric Material as a Function of Frequency and Amplitude of the Applied Voltage. IEEE Trans. Dielectr. Electr. Insul. 2011, 18, 432-443. [CrossRef]

30. Forssen, C. Partial Discharges in Cylindrical Cavities at Variable Frequency of the Applied Voltage. Licentiate's Thesis, KTH Royal Institute of Technology, Stockholm, Sweden, 2005.

31. Borghei, M.; Ghassemi, M. Finite element modeling of partial discharge activity within a spherical cavity in a solid dielectric material under fast, repetitive voltage pulses. In Proceedings of the IEEE Electrical Insulation Conference (EIC), Calgary, AB, Canada, 16-19 June 2019; pp. 34-37.

32. Borghei, M.; Ghassemi, M. Partial discharge finite element analysis under fast, repetitive voltage pulses. In Proceedings of the IEEE Electric Ship Technologies Symposium (ESTS), Arlington, VA, USA, 13-19 August 2019; pp. 324-328.

33. Borghei, M.; Ghassemi, M.; Rodriguez-Serna, J.M.; Albarracin Sanchez, R. Finite Element Analysis and Induced Charge Concept Methods for Internal Partial Discharge Modeling: A Comparison. IEEE Trans. Dielectr. Electr. Insul. 2019, in press.

34. Wang, P.; Cavallini, A.; Montanari, G.C. The Influence of Repetitive Square Wave Voltage Parameters on Enameled Wire Endurance. IEEE Trans. Dielectr. Electr. Insul. 2014, 21, 1276-1284. [CrossRef]

35. Ebke, T.; Khaddour, A.; Peier, D. Degradation of silicone gel by partial discharges due to different defects. In Proceedings of the International Conference on Dielectric Materials, Measurements and Applications, Edinburgh, UK, 17-21 September 2000; pp. 202-207.

36. Chung, J.; Hulbert, G.M. A Time Integration Algorithm for Structural Dynamics with Improved Numerical Dissipation: The Generalized- $\alpha$ Method. J. Appl. Mech. 1993, 60, 371-375. [CrossRef]

(C) 2019 by the authors. Licensee MDPI, Basel, Switzerland. This article is an open access article distributed under the terms and conditions of the Creative Commons Attribution (CC BY) license (http://creativecommons.org/licenses/by/4.0/). 